\title{
Cloning and nucleotide sequence of the carboxynorspermidine decarboxylase gene from Vibrio alginolyticus
}

\author{
Shigeo Yamamoto, Takaya Sugahara, Katsuhiko Tougou \\ and Sumio Shinoda
}

Author for correspondence: Shigeo Yamamoto. Fax: +81862557456.

Faculty of Pharmaceutical Sciences, Okayama University, Tsushima-naka 11-1, Okayama 700, Japan
The gene (nspC) encoding carboxynorspermidine decarboxylase (CANS DC), the last enzyme in norspermidine biosynthesis, in Vibrio alginolyticus was isolated by immuno-screening and its complete nucleotide sequence was determined. Sequence analysis of the subcloned fragment $(2.0 \mathrm{~kb})$ revealed an ORF of 1131 bp encoding a protein of 377 amino acids with a calculated molecular mass of $42008 \mathrm{Da}$. The sequence of $20 \mathrm{~N}$-terminal amino acids of purified CANS $D C$ was found to be identical to that predicted from the nspC gene. A putative ribosome binding sequence was observed 8 bp upstream from the translation start site (ATG), and promoter- and terminator-like sequences were detected upstream and downstream of the ORF, respectively. Database searches identified no similar proteins, but the deduced amino acid sequence contained a putative pyridoxal 5'-phosphate binding region similar to those of the bacterial meso-2,6-diaminopimelate decarboxylases and eukaryotic ornithine decarboxylases. Another full ORF was found on the opposite strand downstream from the nspC gene. It encoded a protein of 69 amino acids with a calculated molecular mass of $7441 \mathrm{Da}$, which exhibited some weak similarity to ScrR, a repressor protein of $V$. alginolyticus, in the helix-turn-helix DNA binding domain, but did not appear to be expressed in the host cells.

Keywords: Vibrio alginolyticus, carboxynorspermidine, decarboxylase gene, polyamines

\section{INTRODUCTION}

In addition to the three prototypical polyamines, putrescine, spermidine and spermine, a wide variety of unusual polyamines, most homologues of the prototypes, such as norspermidine (NSPD) and homospermidine, have been identified particularly in prokaryotes, and recently polyamine analysis has proved to be a valuable tool for chemotaxonomic classification of some bacterial species (Hamana \& Matsuzaki, 1992). However, the amounts of unusual polyamines found in most bacteria seem too low to suggest their functional roles in producer strains. In contrast, members of the genus Vibrio, some of which are important pathogens for humans and animals (Janda et al., 1988), are characterized by possessing NSPD as a main polyamine species instead of spermidine

\footnotetext{
Abbreviations: CANS DC, carboxynorspermidine decarboxylase; NSPD, norspermidine; PLP, pyridoxal 5'-phosphate; DAP DC, meso-2,6diaminopimelate decarboxylase; ODC, ornithine decarboxylase.

The GenBank accession number for the nucleotide sequence data reported in this paper is $D 31783$.
}

(Yamamoto et al., 1990). This is quite a unique type of polyamine occurrence in mesophilic bacteria. In addition, the novel biosynthetic pathways for NSPD in some Vibrio species have been delineated (Fig. 1) (Yamamoto et al., 1986) and the three enzymes responsible have been purified from $V$. alginolyticus (Nakao et al., 1989, 1990, 1991).

The genes involved in biosynthesis of the usual polyamines, putrescine and spermidine, have been cloned from Escherichia coli and extensively characterized (Boyle et al., 1984; Tabor \& Tabor, 1987; Szumanski \& Boyle, 1990; Moore \& Boyle, 1990; biosynthetic ornithine decarboxylase, GenBank accession no. M33766). However, to our knowledge, no genetic study regarding the biosynthetic enzymes for unusual polyamines has been reported. From a viewpoint of the novelty of NSPD biosynthesis in vibrios, it would be of great interest to elucidate the structure, organization and regulation of the genes encoding these enzymes. In addition, isolation and characterization of the genes responsible may provide the means to develop specific DNA probes or PCR primers 


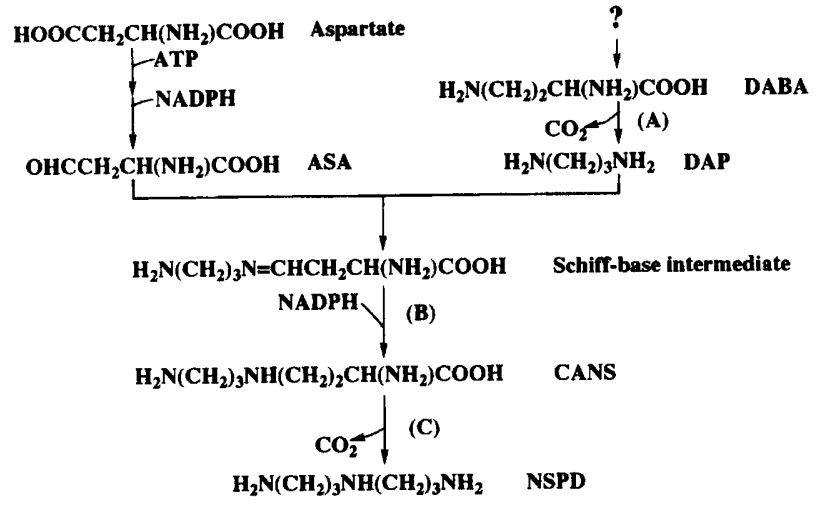

Fig. 1. Biosynthetic pathway for norspermidine in Vibrio species. Enzymes: A, L-2,4-diaminobutyrate decarboxylase; $B$, carboxynorspermidine synthase; C, CANS DC. ASA, aspartic $\beta$ semialdehyde; DABA, L-2,4-diaminobutyrate.

for detection and identification of Vibrio species. Thus, we started to clone the genes involved in NSPD biosynthesis from $V$. alginolyticus.

In this study, we have isolated the gene, named $n s p C$, encoding the pyridoxal 5'-phosphate (PLP)-dependent carboxynorspermidine decarboxylase (CANS DC), catalysing the last step of NSPD biosynthesis, and completely sequenced this gene. The deduced amino acid sequence was compared with those from other bacterial decarboxylases, and Southern hybridization with part of the cloned DNA as a probe was performed to find homologous sequences in other Vibrio species.

\section{METHODS}

Bacterial strains and plasmids. $V$. alginolyticus type strain ATCC 17749 was used as a source of the chromosomal DNA. E. coli HB101 (Boyer \& Roulland-Dussoix, 1969) was used as a host for cloning and sequencing experiments. The plasmids pUC18 and 19 (Norrander $e$ t al., 1983) were used as cloning and subcloning vectors, and pUC19 and pBluescript II SK $(+)$ (Stratagene) as vectors in preparation of unidirectional deletion plasmids for sequencing.

Purification of CANS DC and determination of $\mathbf{N}$-terminal amino acid sequence. CANS DC was purified from $V$. alginolyticus as described by Nakao et al. (1990). The N-terminal amino acid sequence was determined by automated sequential Edman degradation with subsequent identification and quantification of phenylthiohydantoin-labelled amino acids by reversed-phase HPLC.

Antibody preparation. Polyclonal antibodies against purified CANS DC were raised in a rabbit as previously described (Yamamoto et al., 1992). The antiserum was absorbed with sonicated HB101 cells grown in LB broth (Sambrook $t$ t al., 1989).

Western blotting and assay of CANS DC activity. E. coli transformants carrying the recombinant plasmid DNA were cultured in LB broth supplemented with ampicillin at $37^{\circ} \mathrm{C}$ for $8 \mathrm{~h}$. Cells from $200 \mathrm{ml}$ of the culture were harvested by centrifugation and were suspended in $20 \mathrm{mM}$ Tris/ $\mathrm{HCl}, \mathrm{pH} 7 \cdot 5$, containing $1 \mathrm{mM}$ dithiothreitol and $0 \cdot 1 \mathrm{mM}$ EDTA. The cell suspension was disrupted by sonication and the cell debris removed by centrifugation $\left(40000 \mathrm{~g}, 30 \mathrm{~min}\right.$ at $\left.4{ }^{\circ} \mathrm{C}\right)$. The supernatant was used for Western blot analysis and CANS DC assay (Nakao et al., 1990). Western blotting was carried out as follows. A sample of the supernatant (approx. $50 \mu \mathrm{g}$ protein) was separated by SDS-PAGE by the method of Laemmli (1970). The gels were equilibrated in a transfer buffer ( $48 \mathrm{mM}$ Tris, $30 \mathrm{mM}$ glycerol and $20 \%, \mathrm{v} / \mathrm{v}$, methanol) and then transferred electrophoretically $(15 \mathrm{~V}, 30 \mathrm{~min})$ onto nitrocellulose membranes (Hybond-C, Amersham), using a Trans-Blot SD electrophoretic blotting cell (Bio-Rad). The membranes were blocked for $1 \mathrm{~h}$ in TBST $(20 \mathrm{mM}$ Tris, $150 \mathrm{mM} \mathrm{NaCl}, 0.05 \%$ Tween $20, \mathrm{pH} 7 \cdot 5$ ) plus $3 \%$ (w/v) skimmed milk (Difco), and incubated with rabbit antibodies against CANS DC $(1: 500$ dilution) for $1 \mathrm{~h}$. Goat anti-rabbit IgG conjugated to alkaline phosphatase (1:2000 dilution; Boehringer Mannheim) was bound to the membrane in TBST. After washing with TBST, the membrane was visualized by the addition of Nitro Blue Tetrazolium and 5-bromo-4-chloro-3-indolyl phosphate colour development substrates.

Genomic and plasmid DNA isolation. $V$. alginolyticus ATCC 17749 was grown in the modified marine fermentation oxidation medium (Yamamoto et al., 1979) containing $2 \%(\mathrm{w} / \mathrm{v}) \mathrm{NaCl}$ for $8 \mathrm{~h}$ at $37^{\circ} \mathrm{C}$ in a reciprocal waterbath shaker. Cultures were harvested by centrifugation $\left(9800 \mathrm{~g}, 10 \mathrm{~min}\right.$ at $\left.4{ }^{\circ} \mathrm{C}\right)$ during exponential growth $\left(\mathrm{OD}_{660}=0 \cdot 8\right)$. Genomic DNA was prepared by the procedure of Murray \& Thompson (1980) using hexadecyltrimethylammonium bromide. $E$. coli strains harbouring a plasmid were cultivated in LB broth containing $100 \mu \mathrm{g}$ ampicillin $\mathrm{ml}^{-1}$ at $37^{\circ} \mathrm{C}$. Plasmid DNA was isolated by the alkaline extraction procedure of Birnboim \& Doly (1979).

Cloning of the CANS DC (nspC) gene. Genomic DNA from $V$. alginolyticus was partially digested with Sau $3 \mathrm{~A}$, and the fragments $(4-10 \mathrm{~kb})$ collected from an agarose gel were ligated with the DNA ligation kit (Takara Shuzo) into Bam HI-digested pUC19 previously treated with calf intestine alkaline phosphatase (Toyobo) for $30 \mathrm{~min}$ at $37^{\circ} \mathrm{C}$. The ligation mixture was used to transform competent cells of E. coli HB101. Ampicillin-resistant transformants were immobilized on nitrocellulose membranes according to the procedure of Helfman $e t$ al. (1983), and then CANS DC protein-containing colonies were immunologically detected as described for Western blotting. Enzymic manipulation and subcloning of DNA were carried out using standard methods (Sambrook et al., 1989). Restriction enzymes were purchased from Nippon Gene.

Nucleotide sequencing. Unidirectional deletion subclones were prepared by exonuclease III/mung bean nuclease digestion (Kilo-Sequence Deletion kit, Takara Shuzo) with appropriate sets of restriction enzymes according to the manufacturer's recommendations. To determine the span of the CANS DC structural gene, the reactivities to the antiserum of each colony of E. coli HB101 transformed with a deleted plasmid and its crude lysate were monitored by dot blotting and Western blotting, respectively. The plasmid DNA was denatured by treatment with $2 \mathrm{M} \mathrm{NaOH} / 1 \mathrm{mM} \mathrm{Na}{ }_{2}$ EDTA, and the nucleotide sequence of both strands of the cloned DNA was determined by the method of Sanger et al. (1977) using [ $\alpha$ ${ }^{35}$ SICTP and the BcaBEST Dideoxy Sequencing kit (Takara Shuzo). Approximately 300 bases were read from each sample.

DNA hybridization. Total cellular DNAs from $V$. alginolyticus and other pathogenic Vibrio species were digested to completion with $X b a \mathrm{I}$ and separated by electrophoresis. After denaturation by soaking the gel with $0.5 \mathrm{M} \mathrm{NaOH} / 1 \mathrm{M} \mathrm{NaCl}$ for $30 \mathrm{~min}$ at room temperature, the DNA was transferred onto a nylon membrane (Pall) (Southern, 1975) and hybridized with plasmid 
pCDC14-3 (see Fig. 3) as a probe containing the major part of the structural gene of CANS DC. Hybridizations were conducted overnight at $42{ }^{\circ} \mathrm{C}$ in a solution of $5 \times \mathrm{SSC}$ containing $0.1 \%$ sodium $N$-lauroylsarcosine, $3 \%(\mathrm{w} / \mathrm{v})$ casein, $0.02 \%$ SDS and $50 \%(\mathrm{v} / \mathrm{v})$ formamide, and the bands hybridized were visualized by the alkaline phosphatase-conjugated universal probe (Nakagami et al., 1991) (Wakunaga Pharmaceuticals) according to the manufacturer's protocol.

\section{RESULTS AND DISCUSSION}

\section{$\mathrm{N}$-Terminal sequence of CANS DC}

The N-terminal sequence of the CANS DC protein was determined by Edman degradation as MQQNELKTPYFMINEDKLIE.

\section{Cloning of nspC in E. coli HB101}

Prior to screening the pUC19 library, the specificity and titre of the antiserum against CANS DC were determined by immuno-dot blots of both $E$. coli $\mathrm{HB} 101$ and $V$. alginolyticus cells. A 1:500-1000 dilution was determined to give the best positive signal over the $E$. coli background. Of several thousand ampicillin-resistant E. coli transformants tested, one was found to strongly react with the antiserum. Western blots of proteins from this transformant separated by SDS-PAGE identified a band as reacting with the antibodies (Fig. 2). A corresponding band of homology was present in an extract of $V$. alginolyticus but not in that of E. coli HB101 containing pUC19. The crude extract of E. coli HB101 harbouring this clone showed CANS DC activity $\left(1.4 \mu \mathrm{mol} \mathrm{mg}^{-1} \mathrm{~h}^{-1}\right)$ approximately threefold higher than that of $V$. alginolyticus ATCC 17749. However, activities of L-2,4-diamino-

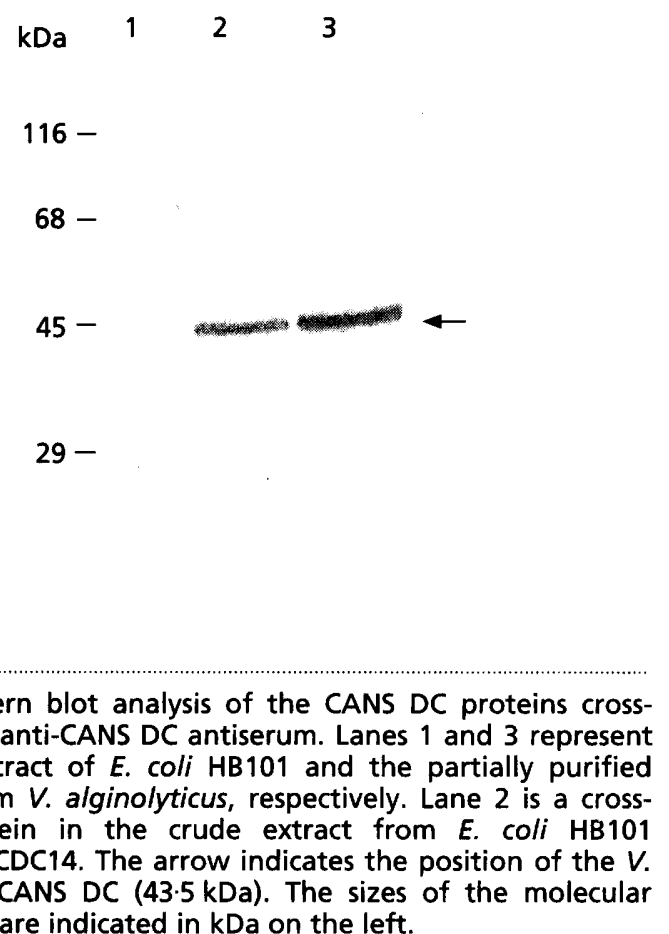

Fig. 2. Western blot analysis of the CANS DC proteins cross reactive with anti-CANS DC antiserum. Lanes 1 and 3 represent the crude extract of $E$. coli $\mathrm{HB} 101$ and the partially purified CANS DC from $V$. alginolyticus, respectively. Lane 2 is a crossreactive protein in the crude extract from $E$. coli $\mathrm{HB101}$ harbouring PCDC14. The arrow indicates the position of the $V$. alginolyticus CANS DC $(43.5 \mathrm{kDa})$. The sizes of the molecular mass markers are indicated in $\mathrm{KDa}$ on the left. butyrate decarboxylase and NSPD synthase, two other enzymes responsible for NSPD biosynthesis, were not detected in the same extract, when assayed by the methods of Nakao et al. $(1989,1991)$. The plasmid recovered from this clone was designated pCDC14, which contained a $4 \mathrm{~kb}$ insert, and was used for further subcloning.

\section{Physical mapping and subcloning for the cloned gene}

Various restriction enzymes were used to generate a physical map of the insert of pCDC14 (Fig. 3). Single restriction sites were found for EcoRI, PvuII and $S a c \mathrm{I}$; two sites each were found for $S a l \mathrm{I}$ and $\mathrm{X} b a \mathrm{I}$. No restriction sites were found for $A p a \mathrm{I}, B a m \mathrm{HI}, \operatorname{DraII}, K p n \mathrm{I}$, NotI, PstI, SmaI, SpeI, SphI and XhoI. This information was used to verify the accuracy of the determined sequence. Subcloning of the $3.6 \mathrm{~kb}$ SacI-Pst I (located within pUC19) fragment of the pCDC14 into pUC18, which was previously digested with the same restriction enzymes, in an inverse orientation with relation to the lac promoter $\left(\mathrm{P}_{\text {lac }}\right)$ ( $\mathrm{pCDC14}$ versus $\mathrm{pCDC} 41$ ) resulted in nearly equal levels of enzyme activity (Fig. 3), indicating that transcription of the $n s p C$ gene is initiated at its own promoter.

To localize the $n s p C$ gene, three deletion subclones were prepared on the basis of the restriction map and were used to transform E. coli $\mathrm{HB} 101$. The results indicated that the $n s p C$ structural gene and its expected promoter were located in the $2.0 \mathrm{~kb}$ EcoRI-Sau3A region containing two $X b a I$ sites (Fig. 3), and this clone was named pCDC14-2. Furthermore, to confirm that the cloned DNA fragment was derived from $V$. alginolyticus, the plasmid, pCDC14-3, containing the $1.2 \mathrm{~kb}$ XbaI fragment from pCDC14 was used to probe the genomic DNA of $V$. alginolyticus by Southern blotting. The probe showed strong hybridization with the $\mathrm{X} b a \mathrm{I}$-digested plasmid pCDC14, which was used as a positive control. Only an identical $1.2 \mathrm{~kb}$ band was visible in the genomic $X b a \mathrm{I}$ digest from $V$. alginolyticus, and no cross-hybridization with the $X b a \mathrm{I}-$ digested E. coli genomic DNA was detected (data not shown), indicating that the $n s p C$ gene is present in $V$. alginolyticus as a single copy.

\section{Nucleotide and deduced amino acid sequence of the nspC gene}

The EcoRI-PstI (vector) fragment of pCDC14-2 was recloned into pBluescript II SK $(+)$ to construct pCDC14$2 \mathrm{SK}$, which was also used to prepare the unidirectional deletion plasmids for sequencing in a reverse direction. A series of nested deletion plasmids were generated from both the SalI and EcoRI sites in pCDC14-2 and pCDC142 SK, respectively. Approximately $500 \mathrm{bp}$ deletions from the EcoRI site resulted in complete disappearance of the protein cross-reactive with the antiserum against CANS DC, suggesting that the possible start site of the $n s p C$ gene is located near the EcoRI site. Hence the $n s p C$ gene is inserted into the pUC19 vector in an opposite orientation with respect to the $P_{\text {lac }}$.

Nucleotide sequence analysis indicated two ORFs, ORF1 (1131 bp) encoding 377 amino acids, and ORF2 (207 bp) 


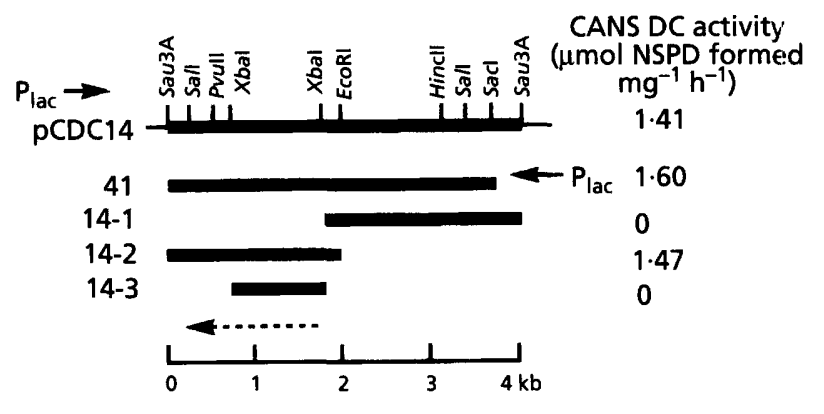

Fig. 3. Restriction map, subclones and deletion derivatives of the plasmid pCDC14. The BamHI site of pUC19 was eliminated by cloning. The thin and bold lines represent pUC19 DNA and $V$. alginolyticus DNA, respectively. CANS DC activity is indicated for each construct. The dotted arrow indicates the position and the direction of the nspC gene.

encoding 69 amino acids (Fig. 4). ORF1 contained a stretch of 20 amino acids, beginning with Met, that corresponded perfectly to the $\mathrm{N}$-terminal part of mature CANS DC as determined by $\mathrm{N}$-terminal sequencing of the protein. This clearly demonstrates that the procedure has led to the cloning of the CANS DC structural gene, and shows that there is no posttranslational modification of the enzyme in the $\mathrm{N}$-terminal part. The ATG start codon was not preceded by a classical ribosome binding site (RBS) (Shine \& Dalgarno, 1974), but the AAGG sequence identical to the RBS in the $V$. alginolyticus scrK gene encoding fructokinase (Blatch et al., 1990) was recognized $8 \mathrm{bp}$ upstream from the start codon. A promoter-like sequence (Harley \& Reynolds, 1987) is located upstream from the start codon with a -35 sequence of TTGCGT followed by a $16 \mathrm{bp}$ space and a -10 region of TATAGT. Interestingly, an inverted repeat with a calculated $\Delta G$ value of $-23.4 \mathrm{kcal} \mathrm{mol}^{-1}$ $\left(-97.9 \mathrm{~kJ} \mathrm{~mol}^{-1}\right)$ spans the -35 region. The positioning of this stem-loop structure would function in gene regulation by blocking access to RNA polymerase. This may be supported by the fact that CANS DC activity in E: coli HB101 harbouring a subcloned plasmid was low compared with levels in $V$. alginolyticus, in spite of the high copy number of the pUC19 vector. Alternatively, it could also act as a terminator site for an undefined upstream ORF. Immediately downstream from the stop codon TAA of the $n s p C$ gene, there is another region of dyad symmetry followed by a TTATT sequence which resembles a $\rho$-independent transcription termination signal (Platt, 1986). The $\Delta G$ value for the formation of this putative terminator structure was calculated to be $-21.5 \mathrm{kcal} \mathrm{mol}^{-1}\left(-89.9 \mathrm{~kJ} \mathrm{~mol}^{-1}\right)$, within the range typically observed for $\rho$-independent terminators.

It was calculated from the deduced amino acid sequence that the exact $M_{\mathrm{r}}$ and $\mathrm{pI}$ of the CANS C subunit were $42008 \mathrm{Da}$ and 4.62 respectively. These values are in reasonable agreement with those reported for CANS DC: $\left(M_{\mathrm{r}} 43500\right.$ and $\left.\mathrm{pI} 4 \cdot 25\right)$ purified from $V$. alginolyticus (Nakao et al., 1990).
The mol $\% \mathrm{G}+\mathrm{C}$ content of the coding region was $47 \cdot 0 \%$, consistent with the $45-47 \%$ overall G $+C$ content in the genomic DNA of $V$. alginolyticus (Baumann \& Schubert, 1984). The codon usage of the $n s p C$ gene was compared with the mean usage calculated from the $V$. alginolyticus collagenase gene (Takeuchi et al., 1992) as well as those of 16 other $V$. alginolyticus genes (Blatch \& Woods, 1991) (data not shown). The percentage synonymous use of each codon in the $n s p C$ gene reflected the bias essentially similar to other $V$. alginolyticus genes. The codons for leucine (CUA), serine (UCA) and threonine (ACA and ACG), which each have been reported to be rare in E. coli genes (Andersson \& Kurland, 1990), were used preferentially in the $n s p C$ gene. In contrast, the preferred codon reported for E. coli for serine (UCC) was not used in the $n s p C$ gene.

\section{Comparison of CANS DC protein sequence with the sequences of other decarboxylases}

The $n s p C$ nucleotide and deduced amino acid sequences were not significantly homologous with any of the sequences of bacterial decarboxylases and other proteins in the current versions of GenBank, EMBL or PIR, suggesting that putative homologous genes in other organisms may not yet have been isolated. In addition, despite the absolute requirement of PLP for CANS DC activity, the deduced amino acid sequence did not show the usual features of a PLP-binding domain, $\mathrm{S}(\mathrm{N}, \mathrm{T})-\mathrm{X}-\mathrm{H}$ $\mathrm{K}$, found in many bacterial $\alpha$-amino acid decarboxylases such as arginine, glutamate, histidine, lysine and ornithine decarboxylases (Smith et al., 1991). Recently, in aligning the amino acid sequences among prokaryotic meso-2,6diaminopimelate decarboxylases (DAP DCs) and eukaryotic ornithine decarboxylases (ODCs), none of which contain the $\mathrm{H}-\mathrm{K}$ sequence, Mills \& Flickinger (1993) identified seven conserved regions and proposed that the consensus lysine residue in the region 1 sequence, $\mathrm{Y}(\mathrm{F})-\mathrm{A}-\mathrm{S}(\mathrm{Q}, \mathrm{V})-\mathrm{K}-\mathrm{A}$ or $\mathrm{C}(\mathrm{S})-\mathrm{F}(\mathrm{N}, \mathrm{C})$ or $\mathrm{N}(\mathrm{H})$, is responsible for Schiff-base formation with PLP in all these decarboxylases. When the deduced amino acid sequence of the $n s p C$ gene product was compared directly with those of the above enzymes, two regions (aa 38-43, L-AL-K-C-F, and 219-224, L-A-L-K-A-F) having significant similarity to the proposed PLP-binding segment were detected (Table 1). Considering the relative position, Lys40 is more likely to be involved in Schiff-base formation. However, the possibility that Lys-222 is involved in PLPbinding cannot be excluded, until more is known about the binding of PLP to this enzyme. Regardless, the occurrence of these conserved segments allowed us to confirm that the $n s p C$ gene encodes one of the structural features typical of a decarboxylase. No similarity to the other regions proposed as catalytic and substrate-binding sites by Mills \& Flickinger (1993), however, could be identified in CANS DC; probably because of differences in structure between CANS and DAP or ornithine substrates. However, eight histidine and seven cysteine residues are present in CANS DC, one of which in each may be associated with the catalytic site. The requirement of dithiothreitol for CANS DC activity (Nakao et al., 


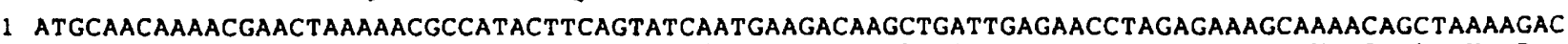

$\begin{array}{lllllllllllllllllllllllllllllll}1 & M & 0 & 0 & N & E & L & K & T & P & Y & F & M & I & N & E & D & K & L & I & E & N & L & E & K & A & K & 0 & L & K & D\end{array}$

LORF I NSPC)

91 ATCTCTGGTGTGAAGCTTGTATTAGCACTGAAGTGCTTCTCAACATGGGGTGTATTCGACATCATCAAGCCTTACCTAGACGGAACAACA

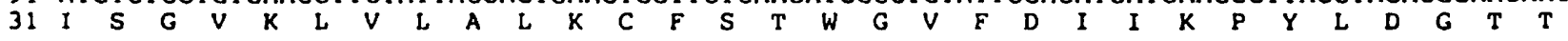

181 AGTTCTGGCCCGTTTGAAGTGAAGCTTGGCTACGAAACGTTCGGTGGTGAGACACACGCATACAGTGTGGGTTACAGCGAAGATGACGTT

$61 \mathrm{~S} S \mathrm{~S} G \mathrm{P} F$ E V K L G Y E T F G G E T H A Y S V G Y S E D D V

271 CGCGATGTGGCGGACATCTGTGACAAGATGATCTTTAACTCTCAGTCACAGCTAGCGGCTTATCGTCATATTGTCGAAGGCAAAGCATCC

$\begin{array}{lllllllllllllllllllllllllllllll}91 & R & D & V & A & D & I & C & D & K & M & I & F & N & S & Q & S & Q & L & A & A & Y & R & H & I & V & E & G & K & A & S\end{array}$

361 ATTGGCTTGCGCCTAAACCCAGGTGTGAGCTATGCAGGGCAAGACTTAGCAAACCCAGCGCGTCAATTCTCTCGTCTTGGTGTTCAGGCT

$\begin{array}{lllllllllllllllllllllllllllllllllll} & 21 & I & G & L & R & L & N & P & G & V & S & Y & A & G & Q & D & L & A & N & P & A & R & Q & F & S & R & L & G & V & Q & A\end{array}$

451 GATCACATCAAACCGGAAATTTTTGATGGTATTGATGGCGTAATGTTCCACATGAACTGTGAGAACAAAGACGTGGATGCGTTTATCGGC

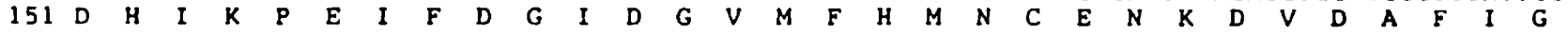

541 TTACTCGATGCTATTTCAGCTCAGTTTGGCGAGTACCTAGATAAGCTGGACTGGGTAAGCATGGGCGGCGGCGTGTTCTTCACATGGCCG

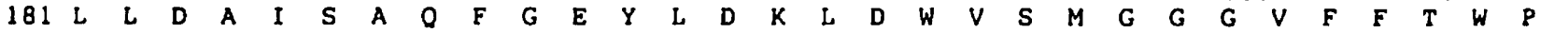

631 GGTTATGACATCGAAAAGCTTGGCCTAGCGCTGAAAGCGTTTGCTGAAAAACACGGCGTGCAAATGTACCTAGAACCGGGCGAACGGATC

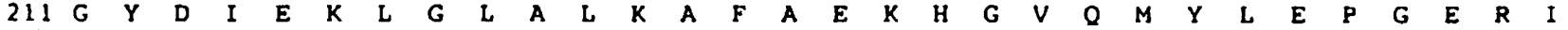

721 ATTACCAAGACGACTGACCTAGTGGTCACTGTGGTTGATATCGTTGAGAACGTAAAGAAGACGGCGATTGTCGATTCAGCCACAGAAGCT

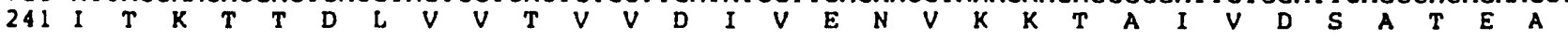

811 CACCGCTTAGATACGTTGATCTACAATGAGCCAGCGTCAATTCTTGAAGCATCTGAAAATGGTGAACACGAGTATGTGATCGGCTCGTGC

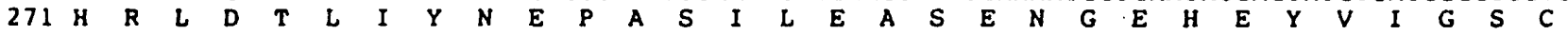
Xbal XbaI

901 TCTTGTTTGGCTGGAGACCAGTTCTGCGTGGCGAACTTCGAACAGCCTCTAGAGATAGGACAGCGTCTGCATATTCTAGATAGTGCCGGT

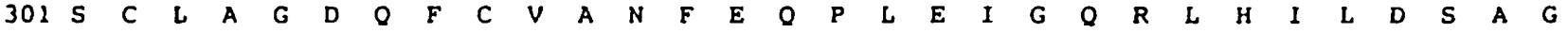

991 TACACCATGGTGAAACTGAACTGGTTTAACGGTCTACGTATGCCGTCGGTCTACTGTGAACGCTCGAATGGTGACATTCAAAAACTGAAT

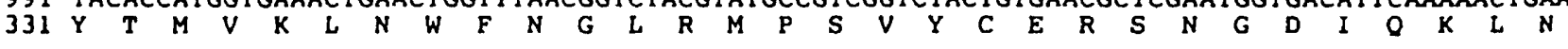

1081 GAATTTGACTACTCTGATTTCAAACGTTCACTGTCTCAGTGGTCAGTGATATAAAACGTATTGAGTATTAGAACGACAAAGAGCAGCTGA

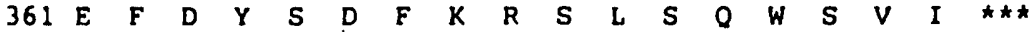

1171 ATTGCTGCTCTTTTTATTGGGGAAGCGTTAAAGGTATGCAGTTAGCTTTCTACAATTACACGAGTGTCTTCACTCAGAGATTCTAACTCA

69

1261 TTGGCTATGTCTTCAATTTCTAGCTCGCTAGGTAGTTTTATCGCCATTTTAGCGCTGAATAAGCTAGAGCTTACCCCTCCGCCTCCTGCA

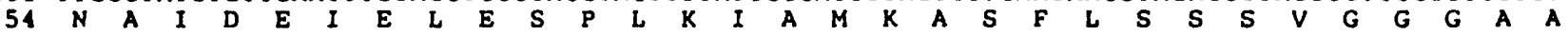

1351 ATGAATACACGGTGACAATCCATATCTAAAATTGAGATACCTTGATTATCGAGAACGTTGAGTAATTTCATTCACAATACCG

$\begin{array}{lllllllllllllllllllllllllllll}24 & I & F & V & R & O & C & D & M & D & L & I & S & I & G & Q & N & D & L & V & N & L & L & K & M\end{array}$
$-10$
$-35$
SalI
ORF $2 \rightarrow$

1441 GTTGGCATCTAAACGAAGTGAaGATAGTGTCTTCACGATATGAGTGAGgCTCAGAGTCGACGAACCTAACAACAAGAGTCTGACAAGAAG

\section{AGAACGCTTGTTTAACGATGTCGGCATTTTCTCTTGGAAGCTCTACTTTGATGACACCTGCAACTTGGTCTTCGATAAAGTTTACTTTGC}

Fig. 4. Nucleotide sequence of the $V$. alginolyticus CANS DC gene, deduced amino acid sequence of the enzyme, and sequences of the 5'- and 3'-flanking regions. The start and the direction of the ORFs are indicated by horizontal arrows. The Shine-Dalgarno ribosome binding sites (RBS) and probable -35 and -10 promoter sequences are underlined. The translation termination codons and a potential transcription termination signal are marked with asterisks and facing arrows, respectively. Relevant restriction sites are indicated above their corresponding recognition sequences. The amino acid sequence as revealed by $\mathrm{N}$-terminal sequencing of the protein is double underlined.

1990) would be accounted for by the involvement of a cysteine residue in the active site.

\section{Nucleotide and deduced amino acid sequences of ORF2}

Sequence analysis also revealed the presence of ORF2 on the opposite strand immediately downstream from the $n s p C$ gene, which is terminated at the putative terminator common with the nspC gene (Fig. 4). The sequence showed a putative RBS, GGGT, a promoter-like sequence (GTGAAG- $\mathrm{N}_{18}$-TTAGAT) upstream from the ATG start codon, and the TAA stop codon followed by a terminator sequence. The translated product of ORF2 would be predicted to have a molecular mass of $7441 \mathrm{Da}$. Part of the deduced amino acid sequence (aa 21-40) displayed some weak similarity to $\operatorname{ScrR}$, a repressor protein of $V$. alginolyticus (Blatch \& Woods, 1991) (data not shown), which has a helix-turn-helix motif typical of prokaryotic DNA-binding proteins (Pabo \& Sauer, 1984). Eleven out of the 20 amino acid residues are identical or belong to the same family, and two of three highly conserved residues are identical. However, the peptide band corresponding to the presumptive product of this gene was not detected by SDS-PAGE in crude lysates of E. coli HB101 harbouring pCDC14-2. This may be that 
Table 1. Similarity of a putative PLP-binding domain of the $V$. alginolyticus CANS DC to those of bacterial DAP DCs and eukaryotic ODCs, all of which lack the conserved amino acid sequence, $-S(N, T)-X-H-K$, for PLP-binding

Identical amino acid residues are marked with asterisks. The PLP-binding domain for eukaryotic ODCs is summarized from the data of Mills \& Flickinger (1993).

\begin{tabular}{|c|c|c|c|}
\hline Organism & Enzyme & $\begin{array}{l}\text { PLP.binding } \\
\text { domain }\end{array}$ & $\begin{array}{c}\text { GenBank } \\
\text { accession } \\
\text { number }\end{array}$ \\
\hline$V$. alginolyticus & CANS DC & 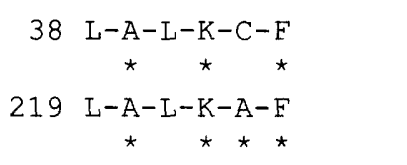 & This study \\
\hline Bacillus subtilis & DAP DC & $\begin{array}{c}65 \mathrm{Y}-\mathrm{A}-\mathrm{S}-\mathrm{K}-\mathrm{A}-\mathrm{F} \\
\star \star \star \star\end{array}$ & D90189 \\
\hline B. methanolicus & DAP DC & 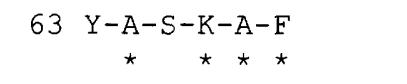 & L188790 \\
\hline Corynebacterium glutamicus & DAP DC & $\begin{array}{c}72 \mathrm{Y}-\mathrm{A}-\mathrm{S}-\mathrm{K}-\mathrm{A}-\mathrm{F} \\
\star \star \star \star\end{array}$ & $\mathrm{X} 07563$ \\
\hline Pseudomonas aeruginosa & DAP DC & 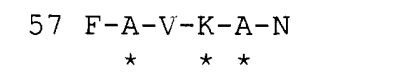 & M23174 \\
\hline E. coli & DAP DC & $\begin{array}{c}51 \mathrm{~F}-\mathrm{A}-\mathrm{Q}-\mathrm{K}-\mathrm{A}-\mathrm{C} \\
\star\end{array}$ & J01614 \\
\hline Eukaryotes & ODCs & $Y(F)-A-S-K-C(S)-N(H)$ & \\
\hline
\end{tabular}

ORF2 is not effectively transcribed or translated in an E: coli background, as is seen with some genes in the plasmid pJM1 of $V$. anguillarum (Farrell et al., 1990).

\section{Genomic hybridization with other Vibrio species}

Genomic DNAs of other Vibrio species completely digested with $X b a I$ were probed with the pCDC14-3 containing a majority of the nspC structural gene to investigate whether homologous sequences could be found. All the strains tested showed a single hybridization band, but surprisingly most of the hybridized fragments were much larger than that of $V$. alginolyticus $(1.2 \mathrm{~kb})$ (Table 2). This, however, at least indicates that the homologous $n s p C$ genes are widely distributed in Vibrio species, presumably reflecting divergence from a common ancestral gene. In accordance with these results, CANS DC activity (Table 2) and a protein with a similar $M_{\mathrm{r}}$ to CANS DC of $V$. alginolyticus, which reacted intensely with the anti-CANS DC antiserum (data not shown), were also found in each cell lysate of the strains, thereby confirming that NSPD in vibrios is indeed synthesized through a novel pathway (Yamamoto et al., 1986). No positive signal was detected for the XbaI-digested genomic DNA from Paracoccus denitrificans NCIB 8944, which produces spermidine from carboxyspermidine through the action of a carboxyspermidine decarboxylase functionally very similar to CANS DC (Tait, 1976).

\section{Conclusions}

The gene encoding CANS DC from $V$. alginolyticus has been cloned and sequenced. Isolation and characterization of the $n s p C$ gene as well as its distribution in other Vibrio
Table 2. Occurrence of the nspC gene in other Vibrio species and their CANS DC activities

Genomic DNA was completely digested with $X b a \mathrm{I}$, separated by electrophoresis, and transferred onto a nylon membrane. Plasmid pCDC14-3 was used as a probe, and the hybridized band was visualized with the alkaline phosphatase-conjugated universal probe (Nakagami et al., 1991). CANS DC activity of the 50-70\% ammonium sulphate precipitate from each strain was determined according to the method of Nakao et al. (1990).

\begin{tabular}{|lcc|}
\hline Strain & $\begin{array}{c}\text { Fragment } \\
\text { hybridized } \\
\text { (kb) }\end{array}$ & $\begin{array}{c}\text { CANS DC } \\
\text { activity } \\
\text { (nmol NSPD } \\
\text { formed } \mathbf{~ m g}^{-1} \\
\mathbf{h}^{-1} \text { ) }\end{array}$ \\
\hline V. anguillarum NCMB 17749 & $10 \cdot 2$ & 540 \\
V. cholerae Non O1 NCTC 8042 & $7 \cdot 2$ & 485 \\
V. cholerae Non O1 NCTC 4716 & $7 \cdot 2$ & 948 \\
V. fuvialis ATCC 33809 & $9 \cdot 7$ & 655 \\
V. furnissii ATCC 35016 & $12 \cdot 0$ & 271 \\
V. bollisae ATCC 33564 & $3 \cdot 2$ & 179 \\
V. mimicus ATCC 33653 & $9 \cdot 7$ & 449 \\
V. parabaemolyticus AQ 3354 & $7 \cdot 2$ & 569 \\
V. parabaemolyticus ATCC 17802 & $7 \cdot 2$ & 799 \\
V. vulnificus CDC A6546 & $7 \cdot 0$ & 371 \\
\hline
\end{tabular}

species demonstrates the existence of the novel biosynthetic route for NSPD, The $n s p C$ gene appeared to be in a separate transcriptional unit, and activities of the two other enzymes, L-2,4-diaminobutyrate decarboxylase and 
CANS synthase, responsible for NSPD biosynthesis were not detected even in the longest clone, pCDC14. Therefore, the organization of NSPD biosynthetic genes differs from that in $E$. coli where the genes essential for spermidine biosynthesis, speE encoding spermidine synthase and speD encoding $S$-adenosylmethionine decarboxylase, constitute an operon (Tabor \& Tabor, 1987). However, since nothing is known about the location of two other genes, whether these genes are located in an operon or closely clustered in the region downstream from the $n s p C$ gene requires further investigation.

A presumptive PLP-binding domain similar to those of DAP DCs from several bacterial sources and of eukaryotic ODCs was identified in the deduced amino acid sequence, but alignments of the nucleotide and deduced amino acid sequences of the $n s p C$ gene with those of these decarboxylase genes revealed no significant homology. In addition, the apparent ubiquity of homologous $n s p C$ genes among Vibrio species was indicated by Southern blot hybridizations. Thus, it is likely that CANS DC may be one of a new family of decarboxylases which have evolved uniquely among Vibrio species. It will be interesting, therefore, to use the $n s p C$ gene as a probe for specific detection of Vibrio species.

In addition to ORF1, ORF2 encoding a possible repressor-like peptide was detected on the opposite strand immediately downstream from ORF1. However, at present there is no evidence that an ORF2 product would be involved in the regulation of ORF1 gene expression.

\section{ACKNOWLEDGEMENTS}

We thank Drs H. Nakao and K. Inagaki for determining the Nterminal amino acid sequence, and Dr T. Moritani for her help in the homology search and data analyses. We thank the Okayama L'niversity Gene Research Center for allowing us to use the Geneline apparatus. This work was supported by a General Grant-in-Aid for Scientific Research from the Ministry of Education, Science, and Culture of Japan.

\section{REFERENCES}

Andersson, S. G. E. \& Kurland, C. G. (1990). Codon preference in free-living microorganisms. Microbiol Rev 54, 198-210.

Baumann, P. \& Schubert, R. H. W. (1984). Family II. Vibrionaceae Veron 1965, 5245 ${ }^{A L}$. In Bergey's Manual of Systematic Bacteriology, Vol. 1, pp. 516-538. Edited by N. R. Krieg \& J. G. Holt. Baltimore: Williams and Wilkins.

Birnboim, H. C. \& Doly, J. (1979). A rapid alkaline extraction procedure for screening recombinant plasmid DNA. Nucleic Acids Res 7, 1513-1523.

Blatch, G. L. \& Woods, D. R. (1991). Nucleotide sequence and analysis of the Vibrio alginolyticus scr repressor-encoding gene $(s c r R)$. Gene 101, $45-50$.

Blatch, G. L., Scholle, R. R. \& Woods, D. R. (1990). Nucleotide sequence and analysis of the Vibrio alginolyticus sucrose uptakeencoding region. Gene $95,17-23$.

Boyer, H. W. \& Roulland-Dussoix, D. (1969). A complementation analysis of the restriction and modification of DNA in Escherichia coli. J Mol Biol 41, 459-472.

Boyle, S. M., Markham, G. D., Hafner, E. W., Wright, J. M., Tabor,
H. \& Tabor, C. W. (1984). Expression of the cloned genes encoding the putrescine biosynthetic enzymes and methionine adenosyltransferase of Escherichia coli (spe A, speB, speC and metK). Gene 30, 129-136.

Farrell, D. H., Mikesell, P., Actis, L. A. \& Crosa, J. H. (1990). A regulatory gene, angR, of the iron uptake system of Vibrio anguillarum: similarity with phage $\mathrm{P} 22$ cro and regulation by iron. Gene 86, 45-51.

Hamana, K. \& Matsuzaki, S. (1992). Polyamines as a chemotaxonomic marker in bacterial systematics. Crit Rev Microbiol 18, 261-283.

Harley, D. K. \& Reynolds, R. P. (1987). Analysis of E. coli promoter sequences. Nucleic Acids Res 15, 2343-2361.

Helfman, D. M., Feramisco, J. R., Fiddes, J. C., Thomas, G. P. \& Hughes, S. H. (1983). Identification of clones that encode chicken tropomyosin by direct immunological screening of a cDNA expression library. Proc Natl Acad Sci US A 80, 31-35.

Janda, J. M., Powers, C., Bryant, R. G. \& Abbott, S. L. (1988). Current perspectives on the epidemiology and pathogenesis of clinically significant Vibrio spp. Clin Microbiol Rev 1, 245-267.

Laemmli, U. K. (1970). Cleavage of structural proteins during assembly of the head of bacteriophage T4. Nature 227, 680-685.

Mills, D. A. \& Flickinger, M. C. (1993). Cloning and sequence analysis of the meso-diaminopimelate decarboxylase gene from Bacillus methanolicus MGA3 and comparison to other decarboxylase genes. Appl Environ Microbiol 59, 2927-2937.

Moore, R. C. \& Boyle, S. M. (1990). Nucleotide sequence and analysis of the spe $A$ gene encoding biosynthetic arginine decarboxylase in Escherichia coli. J Bacteriol 172, 4631-4640.

Murray, M. G. \& Thompson, W. F. (1980). Rapid isolation of highmolecular-weight plant DNA. Nucleic Acids Res 8, 4321-4325.

Nakagami, S., Matsunaga, H., Oka, N. \& Yamane, A. (1991). Preparation of enzyme-conjugated DNA probe and application of the universal probe. Anal Biochem 198, 75-79.

Nakao, H., Ishii, M., Shinoda, S. \& Yamamoto, S. (1989). Purification and some properties of a novel L-2,4-diaminobutyric acid decarboxylase from Vibrio alginolyticus. J Gen Microbiol 135, 345-351.

Nakao, H., Shinoda, S. \& Yamamoto, S. (1990). Purification and properties of carboxynorspermidine decarboxylase, a novel enzyme involved in norspermidine biosynthesis, from Vibrio alginolyticus. $J$ Gen Microbiol 136, 1699-1704.

Nakao, H., Shinoda, S. \& Yamamoto, S. (1991). Purification and some properties of carboxynorspermidine synthase participating in a novel biosynthetic pathway for norspermidine in Vibrio alginolyticus. J. Gen Microbiol 137, 1737-1742.

Norrander, J., Kempe, T. \& Messing, J. (1983). Construction of improved M13 vectors using oligonucleotide-directed mutagenesis. Gene 26, 101-106.

Pabo, C. O. \& Sauer, R. T. (1984). Protein-DNA recognition. Annu Rev Biochem 53, 293-321.

Platt, T. (1986). Transcription termination and regulation of gene expression. Annu Rev Biochem 55, 339-372.

Sambrook, J., Fritsch, E. F. \& Maniatis, T. (1989). Molecular Cloning: a Laboratory Manual, 2nd edn. Cold Spring Harbor, NY: Cold Spring Harbor Laboratory.

Sanger, F., Nicklen, S. \& Coulson, A. R. (1977). DNA sequencing with chain-terminating inhibitors. Proc Natl Acad Sci US A 74, 5463-5467.

Shine, J. \& Dalgarno, L. (1974). The 3'-terminal sequence of Escherichia coli $16 \mathrm{~S}$ ribosomal RNA: complementarity to nonsense 
triplets and ribosome binding site. Proc. Natl Acad Sci US A 71, 1342-1346.

Smith, D. M., Thomas, N. R. \& Gani, D. (1991). A comparison of pyridoxal 5 -phosphate dependent decarboxylase and transaminase enzymes at a molecular level. Experientia 47, 1104-1118.

Southern, E. M. (1975). Detection of specific sequences among DNA fragments separated by gel electrophoresis. $J$ Mol Biol 98, 503-517.

Szumanski, M. B. W. \& Boyle, S. M. (1990). Analysis and sequence of the speB gene encoding agmatine ureohydrolase, a putrescine biosynthetic enzyme in Escherichia coli. J Bacteriol 172, 538-547.

Tabor, C. W. \& Tabor, H. (1987). The spe EspeD operon of Escherichia coli: formation and processing of a proenzyme form of $S$ adenosylmethionine. J Biol Chem 262, 16037-16040.

Tait, G.H. (1976). A new pathway for the biosynthesis of spermidine. Biochem Soc Trans 4, 610-612.

Takeuchi, H., Shibano, Y., Morihara, K., Fukushima, J., Inami, S., Keil, B., Gilles, A., Kawamoto, S. \& Okuda, K. (1992). Structural gene and complete amino acid sequence of Vibrio alginolyticus collagenase. Biochem J 281, 703-708.

Yamamoto, S., Shinoda, S. \& Makita, M. (1979). Occurrence of norspermidine in some species of genera Vibrio and Beneckea. Biochem Biopbys Res Commun 87, 1102-1108.

Yamamoto, S., Hamanaka, K., Suemoto, Y., Ono, B., \& Shinoda, S. (1986). Evidence for the presence of a novel biosynthetic pathway for norspermidine in Vibrio. Can J Mirrobiol 32, 99-103.

Yamamoto, S., Chowdhury, M. A. R., Kuroda, M., Nakano, T., Koumoto, Y. \& Shinoda, S. (1990). Further study on polyamine compositions in Vibrionaceae. Can J Microbiol 37, 148-153.

Yamamoto, S., Tsuzaki, Y., Tougou, K. \& Shinoda, S. (1992). Purification and characterization of $\mathrm{L}$-2,4-diaminobutyrate decarboxylase from Acinetobacter calcoaceticus. J Gen Microbiol 138, 1461-1465.

Received 20 May 1994; revised 18 July 1994; accepted 21 July 1994. 